\title{
Contrast Media Extravasation: Manual versus Power Injector
}

\author{
Tareq Sinan $^{\mathrm{a}}$ Hanaa Al-Khawari ${ }^{\mathrm{a}}$ Fayaz A. Chishti ${ }^{\mathrm{b}}$ Osama M. Al Saeed $^{\mathrm{a}}$ \\ Mehraj Sheikh ${ }^{a}$ \\ a Department of Radiology, Faculty of Medicine, Kuwait University, and bepartment of Clinical Radiology, \\ Al-Amiri Hospital, Ministry of Public Health, Kuwait
}

\section{Key Words}

Intravenous contrast · Complications · Computed tomography

\begin{abstract}
Objective: To compare the incidence and complications of extravasation of low-osmolar nonionic contrast media, injected manually and by the automatic power injector (API). Subjects and Methods: Three thousand five hundred and sixty patients underwent contrast-enhanced abdominal and thoracic computerized tomography scan in the Department of Clinical Radiology, AlAmiri Hospital, Kuwait, between June 1998 and December 2002. These patients were prospectively analyzed for contrast media extravasation, its relation to injection rate, cannula insertion and gauge and its complications. 920 patients were administered low-osmolar nonionic contrast media (Ultravist 300, Omni Paque 240 or 300) intravenously by manual injection and 2,640 patients by automatic power injector. Results: Of the 3,560 patients contrast media extravasation occurred in 11 $(0.3 \%)$. The symptoms were observed in 9 patients $(0.3 \%)$ in the API group and 2 patients $(0.2 \%)$ in the manual injection group, respectively. None of the patients had any soft tissue injury. Conclusion: The incidence of contrast media extravasation is not significantly increased by the use of the API. Low-osmolar nonionic contrast media extravasation resulting from the use of API does not cause any morbidity.
\end{abstract}

Copyright $(\subset) 2005$ S. Karger AG, Basel

\section{KARGER}

Fax +4161306 1234 E-Mail karger@karger.ch www.karger.com

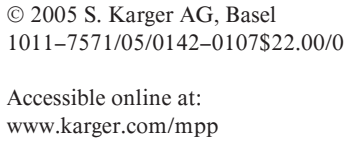

www.karger.com/mpp

\section{Introduction}

Helical computer tomography (HCT) scanners are rapidly replacing conventional computerized tomography (CT) scanners because the HCT technology offers an increased speed of image acquisition and facilitates the detection of visceral diseases by enabling rapid scanning of organs during peak levels of nonionic contrast media (CM) enhancement with minimal respiratory misregistration or motion artifacts $[1,2]$. The automatic power injector (API) enables CM to be delivered as a nonfragmented bolus at a high flow rate, which is essential for many HCT protocols $[3,4]$ such as CT angiography and multiphasic organ imaging. Although the number of reported extravasations has increased since APIs were introduced in CT scanning, the relationship between the frequency of contrast media extravasation (CMEV) to the injection rate remains debatable [5-7].

We conducted a prospective study to compare CMEV in manual injection (MI) and API and its complications. The relation to injection rate, cannula insertion and cannula gauge was also studied.

\section{Subjects and Methods}

Three thousand five hundred and sixty patients, who underwent abdominal and thoracic contrast-enhanced CT in the Department of Clinical Radiology, Al-Amiri Hospital, Kuwait, between June 1998 and December 2002, were included in the study. All scans were obtained with a helical CT scanner (Somotom plus-4 Siemens
Dr. F.A. Chishti

PO Box 8842

22059 Salmiya (Kuwait)

Tel. +965 5744259, Fax +965 5330473

E-Mail fachishti@hotmail.com 
Medical Imaging System) and low-osmolar nonionic CM (Ultravist 300 , Omnipaque 240 or 300) was used. The CM was injected through intravenous (i.v.) cannula to 920 patients manually and 2,640 patients by API. Before the injection of CM, patients were instructed to report if they felt pain at the site of injection. At the end of the procedure, the injection site was examined and a questionnaire was filled in for each patient. Any CMEV was recorded and compared to the rate of injection, i.v. cannula gauge and the personnel inserting the i.v. cannula (radiology or nonradiology trained nurse or physician).

The subjects were categorized into two groups: API group and MI group. The API group was further subdivided into two subgroups based (API 1 and API 2) on the injection rate of up to 2.9 and $3.0-4.5 \mathrm{ml} / \mathrm{s}$, respectively. CMEV was defined as patients complaining of pain at the injection site during administration, with one of the following symptoms: swelling, induration at the site of

Table 1. Cross-tabulation of CMEV by injection method

\begin{tabular}{lllcl}
\hline $\begin{array}{l}\text { Mode of } \\
\text { injection }\end{array}$ & $\begin{array}{l}\text { Total } \\
\text { injections }\end{array}$ & CMEV & No CMEV & $\begin{array}{l}\text { Fisher's } \\
\text { exact test } \\
\text { p value }\end{array}$ \\
\hline API & 2,640 & $9(0.3 \%)$ & 2,631 & $>0.05$ \\
MI & 920 & $2(0.2 \%)$ & 918 & \\
\hline Total & 3,560 & $11(0.3 \%)$ & $3,549(99.7 \%)$ \\
\hline
\end{tabular}

injection and/or suboptimal contrast delivery or enhancement at the region of interest. Patients who complained only of pain without any of the above associated criteria were excluded from the study. Any CMEV was confirmed immediately by CT digital scanogram or plain film at the site of the injection. Analysis of single $2 \times 2$ tables was done using Fisher's exact test. Cutoff for significance was $\mathrm{p}=0.05$.

\section{Results}

Of the 3,560 patients, only $11(0.3 \%)$ had CMEV; 9/2,640 in API and 2/920 in MI groups. The difference was not statistically significant $(p>0.05$, Fisher's exact test; table 1). The incidence of CMEV with $18 \mathrm{G}$ versus $20 \mathrm{G}$ cannulas was comparable irrespective of API or MI use ( $p>0.05$, Fisher's exact test; table 2). Also, CMEV occurrence by injection flow rates in the API 1 and API 2 subgroups were similar regardless of cannula size ( $p>0.05$, Fisher's exact test; table 3 ). There was a slightly higher incidence of CMEV in the API group who had the i.v. cannula inserted by nonradiology staff as compared to radiology staff ( 0.3 vs. $0.2 \%$, respectively, $p>$ 0.05 , Fisher's exact test), but this difference was also not significant (table 4). None of the 11 patients who had CMEV had any soft tissue injury.
Table 2. Incidence of CMEV by cannula gauge

Table 3. Incidence of CMEV by injection flow rates in the API group

\begin{tabular}{lclcrl}
\hline $\begin{array}{l}\text { Mode of } \\
\text { injection }\end{array}$ & $\begin{array}{l}\text { Total } \\
\text { injections }\end{array}$ & Cannula gauge & CMEV & No CMEV & $\begin{array}{l}\text { Fisher's } \\
\text { exact test } \\
\text { p value }\end{array}$ \\
\hline API & 2,640 & $18 \mathrm{G}(\mathrm{n}=1,136)$ & $4(0.3 \%)$ & 1,132 & $>0.05$ \\
MI & 920 & $18 \mathrm{G}(\mathrm{n}=376)$ & $1(0.2 \%)$ & 1,499 & \\
& & $20 \mathrm{G}(\mathrm{n}=544)$ & $1(0.2 \%)$ & 543 & $>0.05$ \\
\hline Total & 3,560 & & 11 & 3,549 & \\
\hline
\end{tabular}

\begin{tabular}{llrrr}
\hline $\begin{array}{l}\text { Cannula } \\
\text { gauge }\end{array}$ & Injection flow rate & CMEV & No CMEV Fisher's \\
& & & $\begin{array}{l}\text { exact test } \\
\text { p value }\end{array}$ \\
\hline $18 \mathrm{G}(\mathrm{n}=1,136)$ & AP1 up to $2.9 \mathrm{ml} / \mathrm{s}(\mathrm{n}=310)$ & $1(0.3 \%)$ & 309 & $>0.05$ \\
& AP2 3-4 ml/s $(\mathrm{n}=826)$ & $3(0.3 \%)$ & 823 & \\
$20 \mathrm{G}(\mathrm{n}=1,504)$ & AP1 up to $2.9 \mathrm{ml} / \mathrm{s}(\mathrm{n}=454)$ & $1(0.2 \%)$ & 453 & $>0.05$ \\
& AP2 3-4 $\mathrm{ml} / \mathrm{s}(\mathrm{n}=1,050)$ & $4(0.3 \%)$ & 1,046 & \\
\hline
\end{tabular}

$\mathrm{n}=$ Total number of injections 
Table 4. Incidence of CMEV by cannula insertion personnel

\begin{tabular}{llllrc}
\hline $\begin{array}{l}\text { Mode of } \\
\text { injection }\end{array}$ & $\begin{array}{l}\text { Total } \\
\text { injections }\end{array}$ & Cannula inserted by & CMEV & No CMEV & $\begin{array}{l}\text { Fishers exact } \\
\text { test } \mathrm{p} \text { value }\end{array}$ \\
\hline API & 2,640 & radiology staff $(\mathrm{n}=1,523)$ & $4(0.2 \%)$ & 1,519 & $>0.05$ \\
MI & \multirow{2}{*}{920} & nonradiology staff $(\mathrm{n}=1,107)$ & $5(0.4 \%)$ & 1,103 & $>0.05$ \\
& & radiology staff $(\mathrm{n}=668)$ & $1(0.1 \%)$ & 251 & 666 \\
\hline
\end{tabular}

\section{Discussion}

CMEV is a well-known complication of contrast-enhanced CT scanning [5-7]. In spite of the radiologist's efforts to prevent CMEV, it continues to occur in every $\mathrm{CT}$ room. In most practices, the reported frequency is less than $1 \%[3,4,7]$. Since the replacement of MI by API, the number of reported CMEV incidents has increased but the relation between CMEV and injection rate remained controversial. Sistrom et al. [5] noted that the frequency of CMEV more than doubled from 0.1 to $0.25 \%$ when the injection rate was increased from 0.5 to $1.5 \mathrm{ml} / \mathrm{s}$. Recent studies conducted with high injection rates suitable for HCT, however, failed to demonstrate such a relationship [6, 8]. In this study no such relationship was found. There was a trend for more CMEV in the API group $(0.3 \%)$ than in the MI group $(0.2 \%)$, and this may be due to the fact that the person who was injecting $\mathrm{CM}$ manually could observe the injection site continuously and at the same time could feel any change in resistance to the flow of CM if extravasation occurred. With the API, on the other hand, CM is injected continuously at a uniform rate even though there is an increase in resistance due to CMEV.

The overall CMEV frequency in our study was $0.3 \%$, which is lower than the rate reported in previous studies $[6,7]$. This variation was not due to the use of large caliber (small gauge) cannulas for high injection rates. Patients who were administered $\mathrm{CM}$ with $20-\mathrm{G}$ and $18-\mathrm{G}$ cannulas, had a maximum injection rate of 2.9 and $4.5 \mathrm{ml} / \mathrm{s}$, respectively. Also, in API subgroups API 1 and API 2, there was no difference in CMEV. The only factor identified that led to a slightly higher incidence of CMEV was cannula insertion by nonradiology staff (trained nurse or a physician) compared to those patients who had the cannula inserted by radiology staff $(0.3$ and $0.2 \%$, respectively). A number of factors could be responsible for the difference: The i.v. cannula inserted by nonradiology staff may have been in place for more than $24 \mathrm{~h}$ or in- serted after multiple attempts, with no extravasation on drip infusion but a leak at high injection flow rates of CM. Both these factors are known to increase the chances of extravasation $[9,10]$. Another factor could be the cannula insertion site because the staff of the Department of Radiology preferred the upper forearm, while the nonradiology staff preferred the dorsum of the hand.

Although no soft tissue injury was observed in this study CMEV could cause severe injuries such as tissue necrosis and compartmental syndrome; other minor sequelae are persistent pain, hypoesthesia, weakness of the limb and difficulty in performing activities of daily life [11]. Nonionic low-osmolar CM is known to reduce the risk of severe soft tissue injury but risk of soft tissue injury is often related to the volume of CMEV. The 11 patients with CMEV were managed conservatively. Patients were reassured that CMEV would not lead to any further complication, advised to apply cold sponges for the next $24 \mathrm{~h}$ and report to the surgical emergency if the pain or swelling persisted. All patients were examined after $24 \mathrm{~h}$ and none of them had an increase in pain and swelling or had reported to surgical emergency. None of the patients developed a soft tissue injury. One reason could be the use of low-osmolar nonionic CM, which is known to have a low incidence of soft tissue injury $[8,12,13]$. Another reason could be the presence of a trained nurse or technologist during the CM injection, closely observing highrisk patients who could not communicate or complain of pain (e.g. unconscious or severely debilitated patients). Once they observed an occurrence of CMEV, they aborted the injection immediately. Thus, the extent of CMEV was minimized and soft tissue injury prevented. Theoretically, the possibility of CMEV occurring in such patients exists if the CM extravasates into deeper tissues, whether injected by MI or API, which can be missed by visual examination and even palpation.

One of the limitations in our study was that patients not diagnosed with CMEV (because of the absence of any accompanying pain or swelling) were not included. In 
such patients, CMEV would have been minimal and insignificant, which is why there was no pain or swelling at the site of CM injection and there was a satisfactory enhancement at the area scanned. Further, such a small extravasation of nonionic low-osmolar CM will not cause any morbidity $[8,12,13]$. The other limitation was regarding the patients who had the cannula inserted by nonradiology staff. They had no record of patient's general condition, the time of cannula placement or the number of attempts made. This needs further study.

\section{Conclusion}

Our data suggest that overall incidence of CMEV was not significantly increased by the use of API and in conjunction with the use of low-osmolar nonionic CM, CMEV did not cause any morbidity in patients undergoing CT examinations.

\section{References}

1 Kalender WA, Sissler W, Klotz E, Vock P: Spiral volumetric CT with single breath hold technique, continuous transport, and continuous scanner rotation. Radiology 1990;176:181183.

2 Heiken JP, Brink JA, Vannier MW: Spiral (helical) CT. Radiology 1993;189:647-656.

- 3 Shuman WP, Adam JJ, Shoenecker SA, Tazioli PR, Moss AA: Use of a power injector during dynamic computed tomography. J Comput Assist Tomogr 1986;10:1000-1002.

- 4 Miles SG, Rasmussen JF, Littwiller T: Safe use of an intravenous power injector for CT: Experience and protocol. Radiology 1990;176:6970 .
5 Sistrom CL, Gay SB, Peffley L: Extravasation of iopamidol and iohexol during contrast-enhanced CT: Report of 28 cases. Radiology 1991;180:707-710.

- 6 Federle MP, Chang PJ, Confer S, Ozgun B: Frequency and effects of extravasation of nonionic contrast media during rapid bolus injection rates. Radiology 1998;206:637-640.

7 Jacobs JE, Birnbaum BA, Langlotz CP: Contrast media reactions and extravasation: Relationship to intravenous injection rates. Radiology 1998;209:411-416.

8 Cohan RH, Dunnick NR, Leder RA, Baker ME: Extravasation media: Efficacy of conservative treatment. Radiology 1990;176:65-67.

9 Lewis GBH, Heckler JF: Radiological examination of failure intravenous infusions. $\mathrm{Br} \mathrm{J}$ Surg 1991;78:500-501.
10 Gault DT: Extravasation injuries. Br J Plast Surg 1993;46:91-96.

11 Cohan RH, Bullard MA, Ellis JH, et al: Local reactions after injection of iodinated contrast material: Detection, management and outcome. Acta Radiol 1997;4:711-818.

12 McAlister WH, Kissane JM: Comparison of soft tissue effects of conventional ionic and non ionic iodine containing contrast material in experimental animals. Pediatr Radiol 1990; 20:170-174.

13 Cohan RJ, Leder RA, Bolick D, et al: Extravascular extravasation of radiographic contrast media: Effects of conventional and low-osmolar agents in the rat thigh. Invest Radiol 1990; 25:504-510. 